\title{
AQUISIÇÃO DE ALIMENTOS DA AGRICULTURA FAMILIAR PARA A ALIMENTAÇÃO ESCOLAR EM SANTA CATARINA, 2012-2014
}

\author{
Carla Rosane Paz Arruda Teo ${ }^{1}$ \\ José Giacomo Baccarin ${ }^{2}$ \\ Rozane Marcia Triches ${ }^{3}$ \\ Junir Antonio Lutinski ${ }^{4}$ \\ Roberta Lamonatto Taglietti ${ }^{5}$
}

\begin{abstract}
Resumo
Este estudo aborda políticas públicas relativas à agricultura familiar e sua relação com a alimentação escolar. O objetivo foi avaliar características da aquisição de alimentos da agricultura familiar para a alimentação escolar em Santa Catarina, em 2012-2014. Trata-se de estudo documental, tendo como fontes de dados documentos de acesso público sobre aplicação de recursos e aquisição de alimentos da agricultura familiar. As variáveis foram: aplicação de recursos, origem e grau de processamento dos alimentos, demanda de alimentos orgânicos, integrais e para necessidades especiais, periodicidade e pontos de entrega, informação sobre preços de aquisição. Foram realizadas análises de frequências e Análise de Componentes Principais (PCA). A proporção de municípios que aplicou $30 \%$ ou mais dos recursos federais recebidos na agricultura familiar variou de 60,2 a 72,2\%. Os 300 editais de compra (chamadas públicas) divulgados por 147 municípios evidenciaram que: $64,2 \%$ dos alimentos demandados eram vegetais; $44,8 \%$ in natura; $14,4 \%$ ultraprocessados. A demanda de alimentos orgânicos, integrais e para necessidades especiais foi incipiente, estando presentes em 21 (7\%), 61 (20,3\%) e $13(4,3 \%)$ editais, respectivamente. A entrega centralizada/pouco descentralizada predominou nos editais (71;23,7\%), com entrega semanal ou entre uma a duas vezes/mês para 87,5\% (1.284) dos alimentos. Informação sobre os preços a serem pagos esteve ausente em 33 (11\%) editais. A PCA explicou 98,1\% da variação de alimentos demandados nas mesorregiões catarinenses, segundo ano e grau de processamento. Conclui-se que a oferta de alimentos na escola tornouse mais saudável; porém, os editais precisam ser mais bem elaborados para favorecer esse processo.
\end{abstract}

Palavras-chave: Alimentação Escolar. Alimentos, Dieta e Nutrição. Colaboração Intersetorial. Programas e Políticas de Nutrição e Alimentação. Serviços de Saúde Escolar.

1 Docente do Programa de Pós-Graduação em Ciências da Saúde da Universidade Comunitária da Região de Chapecó (Unochapecó).carlateo@unochapeco.edu.br.

2 Docente do Programa de Pós-Graduação em Geografia do Instituto de Geociências e Ciências Exatas da Universidade Estadual Paulista Júlio de Mesquita Filho (UNESP). baccarin@fcav.unesp.br.

3 Docente do Programa de Pós-Graduação em Agroecologia e Desenvolvimento Rural Sustentável da Universidade Federal da Fronteira Sul (UFFS) rozane.triches@uffs.edu.br.

4 Docente do Programa de Pós-Graduação em Ciências da Saúde da Universidade Comunitária da Região de Chapecó (Unochapecó).junir@unochapeco.edu.br.

5 Mestra e Doutoranda em Ciências da Saúde do Programa de Pós-Graduação em Ciências da Saúde da Universidade Comunitária da Região de Chapecó (Unochapecó). rotagli@unochapeco.edu.br 


\section{Introdução}

O Programa Nacional de Alimentação Escolar (PNAE) é uma estratégia de segurança alimentar e nutricional e representa uma das mais antigas políticas públicas do Brasil neste campo (SARAIVA et al., 2013). A legislação que rege a execução do programa foi revisada, em 2009, com a Lei Federal no 11.947, cuja aprovação promoveu um salto qualitativo na gestão e operacionalização do PNAE ao vinculá-lo à agricultura familiar. Essa Lei, em seu art. 14, estabelece que um mínimo de 30\% dos recursos repassados aos estados e municípios pelo Fundo Nacional de Desenvolvimento da Educação (FNDE) deve ser empregado na aquisição de alimentos produzidos pela agricultura familiar, preferencialmente local (BRASIL, 2009a).

A partir desse novo marco legal, fica dispensado o procedimento licitatório para a aquisição de produtos da agricultura familiar, desde que os preços sejam compatíveis com os do mercado local e que os alimentos atendam às exigências de qualidade das normas vigentes (BRASIL, 2009a). Frente à dispensa licitatória, foi definida a utilização de um tipo de edital denominado chamada pública como instrumento para aquisição dos produtos da agricultura familiar (BRASIL, 2009b). Assim, o PNAE inaugura, em larga escala, um novo modelo de aquisições públicas no Brasil, cuja simplificação favorece o acesso de pequenos produtores a um relevante mercado institucional e potencializa a inserção de alimentos menos processados na alimentação escolar, respeitando os repertórios alimentares locais e incentivando o consumo de alimentos mais saudáveis. Ao mesmo tempo, fica reforçada a natureza intersetorial desta longeva política pública brasileira.

Em 2010, primeiro ano de vigência da Lei no 11.947/2009 (BRASIL, 2009a), cerca de 47,4\% dos municípios brasileiros adquiriram alimentos da agricultura familiar para o PNAE, aplicando, em média, 22,7\% dos recursos repassados pelo FNDE (SARAIVA et al., 2013). Entre 2010 e 2012, essas proporções avançaram, atingindo $67 \%$ dos municípios brasileiros, com média de $29 \%$ de aplicação dos recursos recebidos. Nesse período, a Região Sul destacou-se tanto no número de municípios que adquiriram da agricultura familiar - que variou de $72 \%$ a $87 \%$ - quanto no percentual médio de recursos aplicados, que evoluiu de $27 \%$ para $37 \%$ (SOARES et al., 2013). Tendo em vista o tempo decorrido desde o início da vigência da Lei no 11.947/2009 (BRASIL, 2009a), e considerando sua complexidade e natureza intersetorial, argumenta-se que seu processo de implementação é relativamente recente e ainda está em curso, sendo pertinente desenvolver pesquisas de delimitação geográfica e temporal abrangentes que evidenciem em que medida a referida lei (BRASIL, 2009a) vem se traduzindo em um perfil mais saudável de aquisição de alimentos para o PNAE. 
Diante dessas ponderações, o objetivo geral deste estudo foi avaliar a aquisição de alimentos da agricultura familiar para a alimentação escolar nos municípios do estado de Santa Catarina, no período de 2012 a 2014, com vistas a contribuir para a produção de avanços no processo de implementação dessa legislação. Como objetivos específicos, este estudo buscou: a) conhecer o nível de atendimento do art. 14 da Lei do PNAE; b) analisar os tipos de alimentos preferencialmente adquiridos da agricultura familiar para o PNAE; c) identificar a adequação das chamadas públicas ao fortalecimento da agricultura familiar e do PNAE.

\section{Agricultura familiar e o Programa Nacional de Alimentação Escolar}

No histórico documental do PNAE, desde sua origem, a indicação da importância de incentivar a compra de alimentos in natura e de produção local esteve presente, com o objetivo principal de redução de custos. A descentralização dos recursos do PNAE, na década de 1990, oportunizou a inclusão de alimentos in natura no cardápio, por meio da compra de alimentos locais que, consequentemente, chegam mais frescos às escolas, o que não era possível com a gestão centralizada, caracterizada pela oferta de alimentos industrializados. Também na década de 1990, com a criação do Programa Nacional de Fortalecimento da Agricultura Familiar (PRONAF), as conferências de Segurança Alimentar e Nutricional (SAN), a retomada do Conselho Nacional de Segurança Alimentar e Nutricional (CONSEA) e a criação do Plano Safra, é que o incentivo e o fortalecimento da agricultura familiar começam a ganhar visibilidade nos documentos oficiais relacionados ao PNAE. Em paralelo, a importância da alimentação saudável também passa a ser incorporada, progressivamente, aos marcos legais do programa, em consonância com o fortalecimento da SAN, especialmente a partir de 2008 (CARVALHOSA; BURLANDY, 2017).

A compra de alimentos provenientes da agricultura familiar, para atender às demandas do PNAE, é uma maneira de reconhecer a necessidade de buscar uma produção de alimentos que atenda às necessidades nutricionais da população e garanta o fortalecimento da agricultura familiar. Nesse sentido, o programa é uma maneira de, simultaneamente, oferecer alimentos mais saudáveis a alunos e estimular a agricultura familiar no País. Dessa forma, o PNAE, dentre suas inúmeras potencialidades, reduz a insegurança alimentar no campo, (re)organiza comunidades, dinamiza a economia local, amplia a oferta de alimentos de qualidade e valoriza a produção familiar (BRASIL, 2014b).

Nesse contexto, vale destacar que o Brasil tem sido modelo em termos de alimentação escolar para outros países, no que se refere à sua organização e, especialmente, ao modelo de aquisição de alimentos da agricultura familiar, 
o qual vem sendo chamado pela literatura internacional de Home-Grown School Feeding (HGSF) e que combina o incentivo à produção agrícola local com melhorias nos programas de alimentação escolar (BUNDY et al., 2009; ESPEJO; BURBANO; GALLIANO, 2009).

Essa aproximação intersetorial tem promovido uma importante transformação na alimentação escolar, pois se apresenta como uma possibilidade de oferta de alimentos mais saudáveis e com vínculo regional, incentivando o resgate de hábitos alimentares e alimentos tradicionais. Além disso, representa um avanço nas metodologias de compras públicas sustentáveis, configurando-se como uma ação de fortalecimento da agricultura familiar, de desenvolvimento regional, de proteção da biodiversidade agrícola e do uso sustentável dos recursos naturais (FAO, 2014; BRASIL, 2016).

Segundo estudo de Gonçalves et al. (2015), é possível observar melhorias na qualidade geral da alimentação escolar com a aquisição de alimentos da agricultura familiar, destacando-se a contribuição positiva que esta prática tem representado no desenvolvimento de bons hábitos alimentares, não apenas pela presença de alimentos saudáveis, mas também pelo uso da produção e do consumo sustentáveis para práticas de Educação Alimentar e Nutricional (EAN). Além disso, espera-se que a presença da agricultura familiar na alimentação escolar aumente o acesso aos alimentos in natura e minimamente processados, reduzindo, consequentemente, o de alimentos processados e ultraprocessados (BRASIL, 2016). É nessa perspectiva que este estudo pretende contribuir, assumindo que a avaliação contínua da implementação de uma política pública é elemento dinamizador de avanços e melhorias (BAPTISTA; MATTOS, 2015), na medida em que permite reconhecer e superar fragilidades e lacunas no processo de conferir-lhe materialidade.

\section{Metodologia}

Foi desenvolvido um estudo de base documental (GIL, 2008), para o qual, inicialmente, foram coletados relatórios disponibilizados em acesso público irrestrito no site do FNDE (BRASIL, 2015a), extraindose deles dados referentes à proporção de recursos aplicados na aquisição de alimentos da agricultura familiar para a alimentação escolar dos 295 municípios catarinenses para os anos de 2012, 2013 e 2014. Compondo a base documental do estudo, foram coletadas as chamadas públicas para compra desses alimentos divulgadas em acesso público nos sites das prefeituras dos 295 municípios de Santa Catarina para os anos de 2012, 2013 e 2014. As chamadas públicas representam a unidade de análise, justificando-se a opção por esta fonte documental pelo fato de a Resolução 
no 26/FNDE/2013 estabelecer que esses editais deverão ser publicados nos sites dos municípios na internet - quando houver (BRASIL, 2013).

Os sites das prefeituras do estado de Santa Catarina foram monitorados regularmente pelos autores, coletando-se as chamadas publicadas. Como critério de inclusão foi adotado o fato de haver, pelo menos, uma chamada pública divulgada pelo município no período de 2012 a 2014, o qual corresponde ao primeiro triênio do monitoramento longitudinal realizado pelo Observatório da aquisição de alimentos da agricultura familiar para a alimentação escolar em Santa Catarina. Este observatório é um projeto matricial que, progressivamente, vem realizando análises sobre diferentes questões relacionadas à aquisição de alimentos da agricultura familiar para o PNAE no estado a partir dos editais de chamada pública.

Das chamadas públicas obtidas, foram coletados dados relativos às seguintes variáveis de estudo: mesorregião (variável grupadora), origem e grau de processamento dos alimentos, presença/ausência de alimentos orgânicos, integrais e para necessidades alimentares especiais; periodicidade e número de pontos de entrega (unidades de recebimento); presença/ ausência de informação sobre os preços de aquisição. Já os dados coletados dos relatórios do FNDE deram origem à variável atendimento do art. 14 da Lei no 11.947/2009 (BRASIL, 2009a).

Foram estabelecidas estas variáveis para o estudo em virtude de o marco legal do PNAE estabelecer a aplicação de 30\% dos recursos na aquisição de alimentos da agricultura familiar para o PNAE, bem como definir o emprego de alimentação saudável e adequada, que atenda a necessidades alimentares específicas e priorize alimentos orgânicos e/ou agroecológicos. A legislação ainda prevê que o preço de aquisição deve ser publicado na chamada pública, assim como o cronograma contendo locais e periodicidade das entregas (BRASIL, 2015b).

Para a análise dos dados, as variáveis de estudo foram categorizadas conforme parâmetros apresentados a seguir: I- Atendimento do art. 14 Lei no 11.947/2009 pelos municípios: não adquiriram alimentos da agricultura familiar; adquiriram, mas não atenderam ao art. 14 (aplicação inferior a $30 \%$ dos recursos); realizaram atendimento legal do art. 14 (aplicação igual ou superior a $30 \%$ e inferior a $40 \%$ ); realizaram atendimento diferenciado (aplicação igual ou superior a 40\% e inferior a 100\%); realizaram atendimento superior (aplicação igual ou superior a 100\%). II- Mesorregião de origem das chamadas públicas: Vale do Itajaí, Grande Florianópolis, Sul Catarinense, Norte Catarinense, Serrana e Oeste Catarinense (IBGE, 2010a). III- Origem dos alimentos: animal, vegetal ou mista. IV- Grau de processamento dos alimentos: in natura; minimamente processados; ingredientes processados; processados; ultraprocessados (BRASIL, 2014a; 
MONTEIRO et al., 2016). V- Alimentos orgânicos, integrais e para necessidades alimentares especiais: consta/não consta na chamada pública. VI- Periodicidade de entrega: duas a cinco vezes por semana; uma vez na semana; uma a duas vezes ao mês; outra (algumas vezes ao ano); não consta a informação (BACCARIN et al., 2017). VII- Número de unidades de recebimento (UR): entrega centralizada (uma UR); entrega pouco descentralizada (duas a dez UR); entrega descentralizada (11 a 50 UR); entrega muito descentralizada (mais de $50 \mathrm{UR}$ ); não consta a informação (BACCARIN et al., 2017). VIII- Preços: consta/não consta a informação.

Algumas das variáveis com as quais este estudo trabalhou não são excludentes entre si, ou seja, um mesmo edital pode solicitar produtos de origem vegetal, animal e mista, assim como alimentos de diferentes graus de processamento. Assim, justifica-se que os totais apresentados na análise dos dados normalmente ultrapassem o número de editais analisados.

Finalmente, além da análise dos dados por estatística descritiva (frequências absoluta e relativa), foi avaliada a associação entre as aquisições por grupos de alimentos segundo o grau de processamento e as mesorregiões de Santa Catarina a partir de uma Análise de Componentes Principais (PCA). A PCA é uma análise dos dados que visa à redução ou eliminação de sobreposições e à escolha das formas mais representativas a partir de combinações lineares. É um método de análise multivariada útil para o reconhecimento de padrões. De forma geral, refere-se a um método estatístico que analisa simultaneamente múltiplas medidas em cada indivíduo ou objeto sob investigação, sendo uma das técnicas mais utilizadas na análise de dados nas diversas áreas do conhecimento (HONGYU; SANDANIELO; OLIVEIRA JUNIOR, 2015). Para tanto, foi construída uma matriz contendo os valores percentuais correspondentes ao número de itens adquiridos de cada grupo de alimentos em relação ao total de itens adquiridos pelos municípios das respectivas mesorregiões. Os grupos de alimentos foram avaliados segundo o grau de processamento, analisados ano a ano e segundo as mesorregiões. A PCA foi construída com o programa estatístico Past (HAMMER; HARPER; RIAN, 2001).

\section{Contexto do Estudo}

O estado de Santa Catarina, localizado na região Sul do Brasil, tem área de 95,7 mil km² e população total de 6.248.436 habitantes (IBGE, 2010a). O estado possui 295 municípios, distribuídos em seis mesorregiões (Vale do Itajaí, Grande Florianópolis, Sul Catarinense, Norte Catarinense, Serrana e Oeste Catarinense), destacando-se pela característica de que $79,7 \%(\mathrm{n}=235)$ destes municípios são de pequeno porte, apresentando população inferior a 20.000 habitantes (IBGE, 2010a). A mesorregião do Vale do Itajaí é formada por 54 municípios, com uma população de 
1.512.059 habitantes e 87,6\% de taxa de urbanização. Já a mesorregião da Grande Florianópolis possui 21 municípios, população de 978.407 habitantes e taxa de urbanização de $92,1 \%$. O Sul Catarinense é formado por 46 municípios, com população de 937.674 habitantes, dos quais $81,4 \%$ residem na zona urbana. A mesorregião Norte Catarinense possui 26 municípios, tem 1.212.843 habitantes e 87,7\% de taxa de urbanização. Já a mesorregião Serrana possui 30 municípios e é a menos populosa do estado, tendo 406.741 habitantes, dos quais $81,7 \%$ residem em área urbana. Finalmente, a mesorregião Oeste Catarinense possui 118 municípios e 1.200.712 habitantes, dos quais 71,7\% residem no meio urbano (IBGE, 2010a). As mesorregiões do Vale do Itajaí, Grande Florianópolis e Norte Catarinense concentram os municípios mais populosos do estado (nove dos 13 que têm mais de 100 mil habitantes), apresentando as maiores taxas de urbanização.

A agropecuária catarinense é das mais dinâmicas e diversificadas do país, tendo sua base produtiva alicerçada na agricultura familiar (ZOLDAN, 2010), que se destaca por uma diversificação produtiva que abrange da produção vegetal à pecuária (MIOR et al., 2014), sobressaindo-se pela participação expressiva na produção estadual de mandioca (93\%), leite (87\%), milho (77\%), feijão (73\%), frangos (68\%), suínos (67\%), bovinos (65\%) e arroz (64\%) (IBGE, 2006). O Censo Agropecuário 2006 apontou a existência de 193.663 estabelecimentos agropecuários em Santa Catarina, dos quais 168.544 (87\%) foram classificados como sendo da agricultura familiar, o que situa o estado entre as unidades da federação que têm os maiores percentuais de agricultores familiares do país (MATTEI, 2010). A importância e o potencial da agricultura familiar em Santa Catarina também ficam evidentes quando são recortados os dados sobre o trabalho no setor: $82 \%$ das pessoas economicamente ativas nos estabelecimentos agropecuários do estado trabalham na agricultura familiar (IBGE, 2006). Apesar desse contexto, a agricultura familiar catarinense também vem enfrentando desafios à sua sobrevivência e reprodução (MARCONDES, 2010), motivo pelo qual o acesso a mercados institucionais, promovido por políticas públicas intersetoriais, surge como uma alternativa para dinamizar o setor, contribuindo, ao mesmo tempo, para qualificar as condições de vida e saúde da população em geral.

\section{Resultados}

Foram obtidos e analisados 300 editais de chamada pública (Tabela 1) referentes ao período de estudo, divulgados por 147 (49,8\%) diferentes municípios do estado. 
Tabela 1 - Frequência de chamadas públicas coletadas e número de municípios correspondentes por mesorregião, Santa Catarina, Brasil, 2012-2014

\begin{tabular}{|c|c|c|c|c|c|c|c|c|c|}
\hline \multirow[t]{2}{*}{ Mesorregião (MR) } & \multirow[t]{2}{*}{ Mun/MR ${ }^{\mathrm{a}}$} & \multicolumn{2}{|c|}{2012} & \multicolumn{2}{|c|}{2013} & \multicolumn{2}{|c|}{2014} & \multicolumn{2}{|c|}{ Total } \\
\hline & & Chamadas ${ }^{\mathrm{b}}$ & Mun $^{c}$ & Chamadas & Mun & Chamadas & Mun & Chamadas & Mun $^{\mathrm{d}}$ \\
\hline Vale do Itajaí & 54 & 12 & 11 & 23 & 15 & 38 & 21 & 73 & 30 \\
\hline $\begin{array}{l}\text { Grande } \\
\text { Florianópolis }\end{array}$ & 21 & 1 & 1 & 3 & 3 & 4 & 4 & 8 & 7 \\
\hline Sul Catarinense & 46 & 0 & 0 & 5 & 5 & 11 & 7 & 16 & 7 \\
\hline Norte Catarinense & 26 & 9 & 7 & 18 & 10 & 17 & 14 & 44 & 18 \\
\hline Serrana & 30 & 3 & 2 & 6 & 5 & 15 & 12 & 24 & 13 \\
\hline Oeste Catarinense & 118 & 14 & 11 & 39 & 26 & 82 & 66 & 135 & 72 \\
\hline Total & 295 & 39 & 32 & 94 & 64 & 167 & 124 & 300 & 147 \\
\hline
\end{tabular}

a Número total de municípios por mesorregião.

b Número de chamadas públicas divulgadas no ano correspondente.

c Número de municípios que divulgaram as chamadas públicas contabilizadas para o ano correspondente.

$\mathrm{d} \mathrm{O}$ número total de municípios não equivale à soma do número de municípios nos três anos estudados, visto que vários municípios se repetem nos diferentes anos.

Fonte: Elaborada pelas autoras a partir das chamadas públicas coletadas em domínio público (2012-2014).

Dos editais analisados, a maior parte foi divulgada por municípios do Oeste Catarinense (135; 45\%), seguido pelo Vale do Itajaí (73;24,3\%), Norte Catarinense (44; 14,7\%), mesorregião Serrana (24; 8\%), Sul Catarinense (16; 5,3\%) e Grande Florianópolis (8; 2,7\%). As chamadas obtidas foram publicadas por municípios que equivalem a $69,2 \%$ daqueles situados no Norte Catarinense, $61 \%$ do Oeste Catarinense, 55,5\% dos municípios do Vale do Itajaí, 43,3\% dos localizados na mesorregião Serrana, 33,3\% da Grande Florianópolis e 15,2\% do Sul Catarinense.

Conforme "Dados Agricultura Familiar 2012-2014", disponibilizados pelo FNDE (BRASIL, 2015a), referentes aos percentuais de recursos aplicados na aquisição de produtos da agricultura familiar pelos municípios catarinenses, em 2012, 2013 e 2014, respectivamente, 291 $(98,6 \%)$ municípios prestaram contas com percentual médio de aquisição de 32,6\%, 293 (99,3\%) com média de 39,6\% e 295 (100\%) com média de $42,2 \%$. Salienta-se que nem todos os municípios que realizaram a prestação de contas informaram algum nível de aquisição da agricultura familiar. Contudo, a frequência dos municípios que atenderam ao art. 14 e a proporção daqueles que apresentaram atendimento diferenciado e/ou superior aumentou ao longo do período de estudo (Tabela 2). 
Tabela 2 - Frequência de municípios de acordo com a faixa de atendimento ao art. 14 da Lei no 11.947/20092, Santa Catarina, Brasil, 2012-2014

\begin{tabular}{|c|c|c|c|c|c|c|}
\hline \multirow{2}{*}{ Municípios segundo a faixa de atendimento ao art. 14} & \multicolumn{2}{|c|}{2012} & \multicolumn{2}{|c|}{2013} & \multicolumn{2}{|c|}{2014} \\
\hline & Mun $^{a}$ & $\%$ & Mun $^{a}$ & $\%$ & Mun $^{a}$ & $\%$ \\
\hline Não adquiriram & 41 & 14,1 & 13 & 4,4 & 25 & 8,5 \\
\hline Adquiriram < 30\% & 75 & 25,8 & 82 & 28,0 & 57 & 19,3 \\
\hline Atendimento legal ( $\geq 30 \%-39,9 \%)$ & 91 & 31,3 & 80 & 27,3 & 50 & 16,9 \\
\hline Atendimento diferenciado ( $\geq 40 \%-99,9 \%)$ & 83 & 28,5 & 112 & 38,2 & 153 & 51,9 \\
\hline Atendimento superior $(\geq 100 \%)$ & 1 & 0,3 & 6 & 2,1 & 10 & 3,4 \\
\hline Total & 291 & 100,0 & 293 & 100,0 & 295 & 100,0 \\
\hline Atenderam $(\geq 30 \%)^{\mathrm{b}}$ & 175 & 60,1 & 198 & 67,6 & 213 & 72,2 \\
\hline
\end{tabular}

a Número de municípios.

b Nesta categoria, estão incluídos os dados apresentados separadamente em "Atendimento legal', 'Atendimento diferenciado' e 'Atendimento superior'.

Fonte: Elaborada pelas autoras com base em Brasil (2015a).

Nas 300 chamadas obtidas, foram listados 9.667 itens alimentares, dos quais $2.329(24,1 \%)$ eram de origem animal, $6.206(64,2 \%)$ de origem vegetal e $1.132(11,7 \%)$ de origem mista, visto que continham ingredientes de origem animal e vegetal. Destacaram-se as mesorregiões Serrana e Grande Florianópolis com os menores percentuais de alimentos de origem animal: $11,2 \%$ e 13,3\%. As mesorregiões Sul e Oeste Catarinense apresentaram as maiores proporções médias destes alimentos, de 30,5\% e 26,9\%, respectivamente. Para o Vale do Itajaí e o Norte Catarinense, os percentuais foram de $23,4 \%$ e $20 \%$. Os alimentos de origem animal mais frequentemente solicitados pelos municípios catarinenses em suas chamadas públicas foram carnes (bovina, suína, de frango e peixe), produtos lácteos (leite, bebida láctea, iogurte, queijo), ovos e mel. Apesar de ter sido identificada alguma variação entre as mesorregiões quanto ao número de itens alimentares de origem animal e vegetal nas 300 chamadas analisadas, $87,7 \%$ (263) delas solicitaram produtos de origem animal e 95\% (285) de origem vegetal.

Observou-se predominância de alimentos in natura durante todo o período de estudo, seguidos dos minimamente processados em todas as mesorregiões. A seguir, com proporções semelhantes, os processados e ultraprocessados; finalmente, os ingredientes processados com as menores proporções (Tabela 3). 
Tabela 3 - Frequência de itens alimentares nas chamadas públicas por mesorregião do estado de acordo com o grau de processamento, Santa Catarina, Brasil, 2012-2014

\begin{tabular}{|c|c|c|c|c|c|}
\hline Mesorregião & Itens Alimentares & 2012 & 2013 & 2014 & Média \\
\hline \multirow[t]{6}{*}{ Vale do Itajaí } & Total de Itens Alimentares & 394 & 797 & 1332 & \\
\hline & $\%$ In Natura & 44,42 & 38,27 & 37,24 & 39,97 \\
\hline & \% Minimamente Processados & 21,83 & 25,60 & 26,58 & 24,67 \\
\hline & \% Ingredientes Processados & 4,31 & 5,02 & 4,80 & 4,71 \\
\hline & \% Processados & 15,23 & 13,93 & 10,96 & 13,37 \\
\hline & $\%$ Ultraprocessados & 14,21 & 17,19 & 20,42 & 17,27 \\
\hline \multirow[t]{6}{*}{ G. Florianópolis } & Total de Itens Alimentares & 9 & 101 & 163 & \\
\hline & $\%$ In Natura & 88,89 & 73,27 & 47,24 & 69,80 \\
\hline & $\%$ Minimamente Processados & 11,11 & 16,83 & 19,02 & 15,65 \\
\hline & \% Ingredientes Processados & 0,00 & 0,99 & 4,91 & 1,97 \\
\hline & $\%$ Processados & 0,00 & 5,94 & 16,56 & 7,50 \\
\hline & \% Ultraprocessados & 0,00 & 2,97 & 12,27 & 5,08 \\
\hline \multirow[t]{6}{*}{ Sul Catarinense } & Total de Itens Alimentares & 0 & 201 & 444 & \\
\hline & $\%$ In Natura & 0,00 & 22,39 & 31,76 & 18,05 \\
\hline & \% Minimamente Processados & 0,00 & 30,85 & 28,15 & 19,67 \\
\hline & \% Ingredientes Processados & 0,00 & 5,47 & 3,83 & 3,10 \\
\hline & $\%$ Processados & 0,00 & 18,91 & 12,39 & 10,43 \\
\hline & $\%$ Ultraprocessados & 0,00 & 22,39 & 23,87 & 15,42 \\
\hline \multirow[t]{6}{*}{ Norte Catarinense } & Total de Itens Alimentares & 271 & 452 & 583 & \\
\hline & $\%$ In Natura & 43,54 & 56,19 & 54,20 & 51,31 \\
\hline & \% Minimamente Processados & 21,40 & 19,69 & 18,18 & 19,76 \\
\hline & \% Ingredientes Processados & 2,95 & 2,43 & 3,09 & 2,82 \\
\hline & \% Processados & 15,87 & 11,50 & 13,38 & 13,58 \\
\hline & \% Ultraprocessados & 16,24 & 10,18 & 11,15 & 12,52 \\
\hline \multirow[t]{6}{*}{ Região Serrana } & Total de Itens Alimentares & 56 & 131 & 648 & \\
\hline & $\%$ In Natura & 82,14 & 76,34 & 58,02 & 72,17 \\
\hline & \% Minimamente Processados & 12,50 & 13,74 & 19,29 & 15,18 \\
\hline & \% Ingredientes Processados & 0,00 & 0,76 & 2,31 & 1,03 \\
\hline & \% Processados & 1,79 & 5,34 & 11,11 & 6,08 \\
\hline & $\%$ Ultraprocessados & 3,57 & 3,82 & 9,26 & 5,55 \\
\hline \multirow[t]{6}{*}{ Oeste Catarinense } & Total de Itens Alimentares & 408 & 1140 & 2537 & \\
\hline & $\%$ In Natura & 42,65 & 42,46 & 43,52 & 42,87 \\
\hline & \% Minimamente Processados & 20,10 & 23,25 & 24,48 & 22,61 \\
\hline & \% Ingredientes Processados & 5,15 & 5,00 & 4,69 & 4,95 \\
\hline & $\%$ Processados & 18,63 & 14,04 & 14,66 & 15,78 \\
\hline & \% Ultraprocessados & 13,48 & 15,26 & 12,65 & 13,80 \\
\hline \multirow[t]{6}{*}{ Total SC } & Total de Itens Alimentares & 1138 & 2822 & 5707 & \\
\hline & \% In Natura & 45,78 & 44,72 & 43,98 & 44,83 \\
\hline & \% Minimamente Processados & 20,56 & 23,21 & 23,87 & 22,55 \\
\hline & \% Ingredientes Processados & 4,04 & 4,29 & 4,22 & 4,18 \\
\hline & $\%$ Processados & 15,82 & 13,25 & 13,14 & 14,07 \\
\hline & $\%$ Ultraprocessados & 13,80 & 14,53 & 14,79 & 14,37 \\
\hline
\end{tabular}

Fonte: Elaborada pelas autoras a partir das chamadas públicas coletadas em domínio público (2012-2014). 
Ao todo, 98,1\% da variação dos alimentos listados nas chamadas públicas nas mesorregiões catarinenses, segundo o grau de processamento, foi explicada pela PCA. As chamadas das mesorregiões Grande Florianópolis e Serrana, em 2012 e 2013, apresentaram associação positiva com o grupo de alimentos in natura. Os percentuais dos minimamente processados, ingredientes processados, processados e ultraprocessados foram similares nas seis mesorregiões, nos três anos avaliados, com exceção do Sul Catarinense, em 2012, período em que não foram encontrados editais (Figura 1).

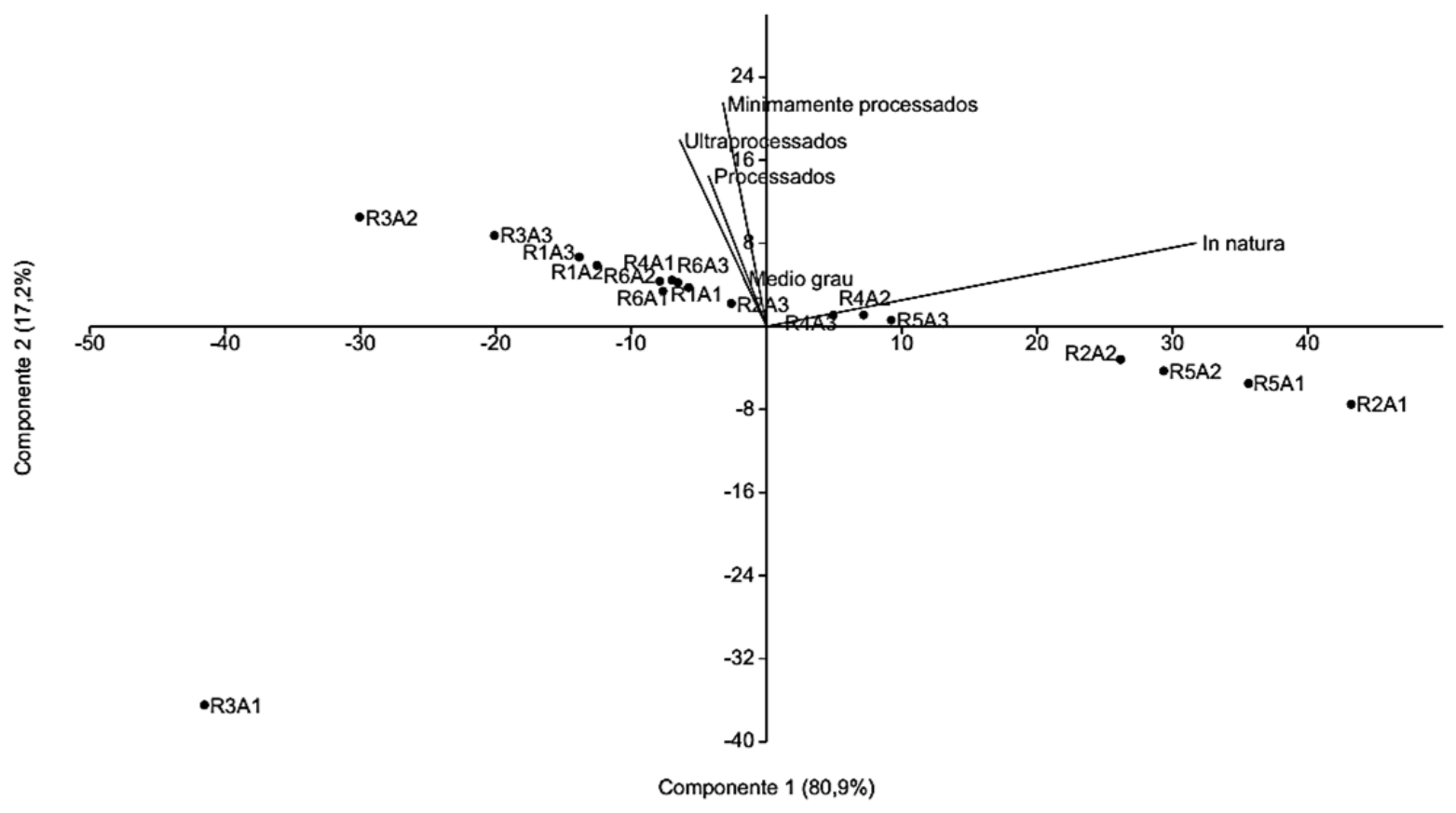

Figura 1 - Associação, pela análise de componentes principais, entre os grupos de alimentos nos editais analisados, segundo o grau de processamento, e as mesorregiões de Santa Catarina, 2012 a 2014

R1: Vale do Itajaí; R2: Grande Florianópolis; R3: Sul Catarinense; R4: Norte Catarinense; R5: Região Serrana; R6: Oeste Catarinense; A1: ano 2012; A2: ano 2013; A3: ano 2014.

Fonte: Elaborada pelas autoras a partir das chamadas públicas coletadas em domínio público (2012-2014). 
Com relação à periodicidade de entrega, levou-se em consideração o número de produtos listados nas chamadas públicas e que têm indicação dessa informação $(1.468 ; 15,2 \%)$. Nesta análise, constatou-se solicitação de entrega semanal ou entre uma e duas vezes ao mês para 87,5\% (1.284) dos alimentos. Para o número de pontos de entrega (Tabela 4), ou unidades de recebimento (UR), a maior parte das chamadas não apresentou esta informação (178; 59,3\%), com destaque para Oeste Catarinense e Vale do Itajaí.

Tabela 4 - Frequência de chamadas públicas com relação ao número de unidades de recebimento (UR), por mesorregião, Santa Catarina, Brasil, 2012-2014

\begin{tabular}{|c|c|c|c|c|c|c|}
\hline Mesorregião & Chamadas & 2012 & 2013 & 2014 & Total & $\%^{\mathrm{a}}$ \\
\hline Vale do Itajaí & Número de Chamadas & 12 & 23 & 38 & 73 & --- \\
\hline \multirow{5}{*}{ Número de UR } & 1 & 1 & 1 & 1 & 3 & 11,5 \\
\hline & 2 a 10 & 1 & 2 & 6 & 9 & 34,6 \\
\hline & 11 a 50 & 3 & 2 & 6 & 11 & 42,4 \\
\hline & Mais de 50 & 1 & 2 & 0 & 3 & 11,5 \\
\hline & Não consta & 6 & 16 & 25 & 47 & 64,4 \\
\hline Grande Florianópolis & Número de Chamadas & 1 & 3 & 4 & 8 & --- \\
\hline \multirow{5}{*}{ Número de UR } & 1 & 0 & 0 & 1 & 1 & 20,0 \\
\hline & 2 a 10 & 0 & 0 & 2 & 2 & 40,0 \\
\hline & 11 a 50 & 0 & 1 & 1 & 2 & 40,0 \\
\hline & Mais de 50 & 0 & 0 & 0 & 0 & 0,0 \\
\hline & Não consta & 1 & 2 & 0 & 3 & 37,5 \\
\hline Sul Catarinense & Número de Chamadas & 0 & 5 & 11 & 16 & --- \\
\hline \multirow{5}{*}{ Número de UR } & 1 & 0 & 1 & 1 & 2 & 28,6 \\
\hline & 2 a 10 & 0 & 0 & 2 & 2 & 28,6 \\
\hline & 11 a 50 & 0 & 1 & 2 & 3 & 42,8 \\
\hline & Mais de 50 & 0 & 0 & 0 & 0 & 0,0 \\
\hline & Não consta & 0 & 3 & 6 & 9 & 56,2 \\
\hline Norte Catarinense & Número de Chamadas & 9 & 18 & 17 & 44 & --- \\
\hline \multirow{5}{*}{ Número de UR } & 1 & 0 & 0 & 0 & 0 & $\overline{0,0}$ \\
\hline & 2 a 10 & 0 & 0 & 4 & 4 & 16,7 \\
\hline & 11 a 50 & 3 & 8 & 4 & 15 & 62,5 \\
\hline & Mais de 50 & 2 & 2 & 1 & 5 & 20,8 \\
\hline & Não consta & 4 & 8 & 8 & 20 & 45,4 \\
\hline Serrana & Número de Chamadas & 3 & 6 & 15 & 24 & -- \\
\hline \multirow{5}{*}{ Número de UR } & 1 & 1 & 2 & 2 & 5 & 35,7 \\
\hline & 2 a 10 & 2 & 2 & 2 & 6 & 42,9 \\
\hline & 11 a 50 & 0 & 1 & 2 & 3 & 21,4 \\
\hline & Mais de 50 & 0 & 0 & 0 & 0 & 0,0 \\
\hline & Não consta & 0 & 1 & 9 & 10 & 41,7 \\
\hline Oeste Catarinense & Número de Chamadas & 14 & 39 & 82 & 135 & --- \\
\hline
\end{tabular}




\begin{tabular}{|c|c|c|c|c|c|c|}
\hline \multirow{5}{*}{ Número de UR } & 1 & 5 & 4 & 12 & 21 & 45,6 \\
\hline & 2 a 10 & 2 & 2 & 12 & 16 & 34,8 \\
\hline & 11 a 50 & 0 & 1 & 4 & 5 & 10,9 \\
\hline & Mais de 50 & 1 & 2 & 1 & 4 & 8,7 \\
\hline & Não consta & 6 & 30 & 53 & 89 & 65,9 \\
\hline Total SC & Número de Chamadas & 39 & 94 & 167 & 300 & --- \\
\hline Mesorregião & Chamadas & 2012 & 2013 & 2014 & Total & $\%^{\mathrm{a}}$ \\
\hline \multirow{5}{*}{ Número de UR } & 1 & 7 & 8 & 17 & 32 & 26,2 \\
\hline & 2 a 10 & 5 & 6 & 28 & 39 & 32,0 \\
\hline & 11 a 50 & 6 & 14 & 19 & 39 & 32,0 \\
\hline & Mais de 50 & 4 & 6 & 2 & 12 & 9,8 \\
\hline & Não consta & 17 & 60 & 101 & 178 & 59,3 \\
\hline
\end{tabular}

a Os percentuais apresentados para "Número de Chamadas" de todas as categorias entre " 1 " a "Mais de 50" foram calculados sobre o total de chamadas que dispunham dessa informação; o percentual apresentado para "Número de Chamadas" na categoria "Não consta" foi calculado sobre o total de chamadas publicadas.

Fonte: Elaborada pelas autoras a partir das chamadas públicas coletadas em domínio público (2012-2014).

Considerando as chamadas que continham informação sobre o número de UR (122; 40,7\%), a entrega descentralizada (11 a 50 UR) e a muito descentralizada (mais de $50 \mathrm{UR}$ ), somadas, predominaram no Vale do Itajaí e Norte Catarinense. A entrega muito descentralizada apenas foi identificada no Vale do Itajaí, Norte e Oeste Catarinense. Nas mesorregiões Grande Florianópolis, Sul Catarinense, Serrana e Oeste Catarinense predominaram as entregas centralizadas (uma UR) ou pouco descentralizadas (duas a 10 UR).

Foi constatado que 11\% (33) das chamadas públicas não continham informação sobre os preços a serem pagos pelos alimentos aos agricultores. Porém, ocorreu um aumento gradativo na disponibilização dessa informação nas chamadas no período avaliado, índice que passou de 82\% (32) em 2012 para 88,3\% (83) em 2013 e 91\% (152) em 2014.

A análise também evidenciou um nível inexpressivo de aquisição de alimentos orgânicos da agricultura familiar para a alimentação escolar em Santa Catarina, observando-se que apenas 7\% (21) dos editais apresentavam algum alimento orgânico. Estes editais eram das mesorregiões Vale do Itajaí, Norte e Oeste Catarinense. A proporção de chamadas dessas mesorregiões que continham alimentos orgânicos diminuiu, ao longo do período avaliado, tendo sido de 15,4\% (6) em 2012, 7,4\% (7) em 2013 e $4,8 \%$ (8) em 2014. Com relação aos alimentos integrais, o período em que estiveram mais presentes nas chamadas públicas, em todas as mesorregiões, foi o ano de 2013 (27; 28,7\%). Este indicador foi de 15,4\% (6) em 2012 e de $16,8 \%$ (28) em 2014. 
A compra de gêneros para necessidades alimentares especiais, como intolerância à lactose e/ou glúten, foi incipiente (13; 4,3\%), localizando-se algum alimento destas categorias apenas nas chamadas públicas dos anos de 2013 (3; 3,2\%) e 2014 (10; 6\%). Salienta-se que nenhuma das chamadas públicas da mesorregião Serrana apresentou algum produto com vistas ao atendimento de necessidades alimentares especiais de escolares ao longo do período de estudo.

\section{Discussão}

Neste estudo, foram localizadas chamadas públicas de um número de municípios inferior ao daqueles que, segundo o FNDE (BRASIL, 2015a), informaram, em suas prestações de contas, alguma aquisição de alimentos da agricultura familiar para a alimentação escolar nos anos de 2012, 2013 e 2014 (250, 280 e 270 municípios, respectivamente). Assim, supõe-se que a divulgação das chamadas públicas no estado ainda não seja tão ampla quanto prevê a legislação vigente (BRASIL, 2013), visto que a quase totalidade dos municípios dispõe de sites oficiais, mas apenas em 147 deles foi possível localizar alguma chamada púbica no período. Essa constatação pode, ainda, ser explicada pela possibilidade de que a compra da agricultura familiar seja viabilizada por outros mecanismos, visto que têm sido reportadas resistências para o uso das chamadas públicas em substituição às licitações convencionais (BACCARIN et al., 2017).

No entanto, observa-se um movimento crescente em todas as mesorregiões do estado no sentido da aquisição de alimentos da agricultura familiar para a alimentação escolar, tanto em termos do número de chamadas publicadas quanto do número de municípios que publicaram chamadas. Esse movimento, apesar de atingir todo o estado, foi mais intenso nas mesorregiões Sul, Serrana e Oeste Catarinense (Tabela 1), sugerindo-se que suas menores taxas de urbanização (81,4\%, 81,7\% e 71,7\%, respectivamente) e a concentração de municípios com menor população contribuam para explicar esta observação (IBGE, 2010a).

A proporção de municípios que atenderam ao disposto no art. 14 da Lei no 11.947/2009 (BRASIL, 2009a) foi elevada e crescente no período, tendo passado de 60,2\% em 2012 para 72,2\% em 2014. O mesmo foi observado quanto ao percentual de municípios que apresentaram atendimento diferenciado, aplicando de $40 \%$ a $99,9 \%$ dos recursos em alimentos da agricultura familiar. Entre os municípios que atenderam ao art. 14, também se constatou um aumento da proporção daqueles que o fizeram em nível superior, com aplicação igual ou superior a 100\% dos recursos recebidos do FNDE na aquisição da agricultura familiar. Isso é possível quando os municípios também destinam para esse fim 
recursos próprios, em complementação àqueles recebidos do FNDE, o que é denominado como contrapartida (BRASIL, 2017). Esses dados condizem com os de Saraiva et al. (2013), que, ao traçarem o panorama nacional da compra de alimentos da agricultura familiar para o PNAE, em 2010, afirmaram que a região Sul do país apresentou o maior percentual, o que, conforme sugeriram, estaria relacionado ao nível de organização dos produtores rurais e dos gestores da região, em prol de maior agilidade na implementação da legislação.

A elevada proporção de municípios que solicitaram alimentos de origem animal nas chamadas públicas indica que a agricultura familiar de Santa Catarina esteja bem adaptada aos regramentos para o fornecimento destes alimentos, uma vez que carnes e produtos lácteos dependem de transformação em plantas industriais, além de fiscalização por serviços públicos de inspeção, salientando-se que as questões sanitárias figuram entre os principais entraves para uma maior inserção da agricultura familiar na alimentação escolar (TRICHES; SCHNEIDER, 2010; BACCARIN et al., 2017). As maiores proporções médias destes alimentos observadas nas chamadas do Sul e Oeste Catarinense podem ser indicativas de que a agricultura familiar esteja mais preparada para atender às exigências sanitárias para alimentos de origem animal, mais rigorosas do que as dos vegetais (TRICHES; SCHNEIDER, 2012). Além disso, nestas mesorregiões, pode ser maior e mais eficaz a divulgação do processo de aquisição de alimentos da agricultura familiar, gerando melhor entendimento entre os agricultores sobre o processo de fornecimento para o PNAE. Essa hipótese parece ser reforçada pela constatação de que estas mesorregiões estiveram entre as que apresentaram, proporcionalmente, os mais expressivos aumentos no número de chamadas divulgadas e no número de municípios que publicaram chamadas no período de 2012 a 2014.

Contudo, há que se considerar, também, que esse aumento do número de chamadas publicadas, associado às maiores proporções de alimentos de origem animal observadas, pode indicar uma maior vontade política dos gestores envolvidos, o que tem se mostrado fundamental para a superação dos entraves à inclusão da agricultura familiar no PNAE (TRICHES; SCHNEIDER 2012; BACCARIN et al., 2017; TEO; MOSSMANN; TAGLIETTI, 2017). Além disso, a literatura tem apontado que uma política se torna realidade a partir da leitura que fazem dela aqueles que a colocam em ação, em um movimento que não está isento de disputas e interesses diversos (MOSSMANN; TEO, 2017).

A predominância de produtos vegetais nos documentos analisados indica que a aquisição da agricultura familiar vem intensificando a inserção desses alimentos na alimentação escolar, o que a priori é avaliado como positivo (TEO; MONTEIRO, 2012), restando importante avaliar seu grau 
de processamento. Nessa direção, constatou-se a predominância de alimentos in natura e minimamente processados nos editais analisados, em todas as mesorregiões, o que é compatível com as recomendações do Guia Alimentar Brasileiro (BRASIL, 2014a) e, também, com o importante papel da escola na promoção de alimentação saudável (DOMENE, 2008; CERVATOMANCUSO et al., 2013). Esses dados são condizentes com os de um estudo realizado em 2013, que indicou a predominância de alimentos in natura, especialmente frutas (31\%) e hortaliças (50\%), em chamadas públicas do estado de São Paulo (AMORIM; ROSSO; BANDONI, 2016).

No entanto, considerando os efeitos adversos à saúde ligados ao consumo regular de alimentos ultraprocessados - caracterizados por baixa densidade nutricional (LOUZADA et al., 2015) - e, ainda, as restrições a esses alimentos apresentadas pela Resolução no 26, do FNDE de 2013 (BRASIL, 2013), pondera-se que os percentuais observados de alimentos desta categoria são elevados, com destaque para o Vale do Itajaí e Sul Catarinense. Esse achado pode estar relacionado ao entendimento ou à vontade política dos diversos atores envolvidos nesse processo. Porém, outros estudos, com diferentes abordagens metodológicas - que permitam avaliar, por exemplo, as quantidades per capita ofertadas, assim como reconhecer percepções e disposições políticas -, precisam ser desenvolvidos para que se possa avançar nessa discussão.

O fato é que, a partir dos dados obtidos no presente estudo, sugerese que, em algumas mesorregiões, a aquisição da agricultura familiar para o PNAE vem se caracterizando por aumento das proporções de alimentos in natura e minimamente processados acompanhado de redução daquelas dos ultraprocessados, como no Norte e no Oeste Catarinense. Já em outras, como na Grande Florianópolis e na Serrana, parece ter ocorrido um movimento em sentido contrário no período avaliado.

Muitos dos produtos ultraprocessados listados nos editais analisados, provavelmente, não são produzidos por agricultores familiares individuais, devido à sua pouca infraestrutura, estimando-se que possam ser predominantemente fornecidos por cooperativas. Reforça-se que estes não são os produtos mais adequados para a alimentação escolar, tendo em conta seu objetivo de contribuir para a formação de hábitos alimentares saudáveis.

Salienta-se que inquéritos nacionais, desenvolvidos no Brasil, têm evidenciado declínio do consumo de alimentos tradicionais básicos, como arroz, feijão, batata, mandioca, e insuficiência do consumo de frutas e hortaliças, ao mesmo tempo em que se intensifica o consumo de produtos com grau crescente de processamento, como biscoitos, refrigerantes e preparações prontas para aquecer/comer, assim como vem aumentando a ingestão de açúcares simples e sal ocultos em produtos processados, e de gorduras totais e saturadas (IBGE, 2010b). 
Dessa forma, ganha relevo a temática da articulação entre a agricultura familiar e as políticas de segurança alimentar e nutricional, como o PNAE. Argumenta-se que a atenção não deve estar apenas nos aspectos econômico-financeiros da alocação e da destinação de recursos ou, ainda, assumir um viés legalista de cumprimento (ou não) de determinados dispositivos, embora todas essas questões sejam importantes. É preciso, de forma ampliada e atendendo aos princípios da intersetorialidade, compatibilizar os diversos interesses que estão em pauta, considerando o tipo de oferta alimentar em que a aproximação com a agricultura familiar vem se traduzindo para a comunidade escolar.

Assim, avaliar o grau de processamento dos alimentos presentes nas chamadas públicas parece ser um bom indicador de como esta política vem ganhando materialidade, especialmente na perspectiva da promoção da saúde, considerando suas dimensões em termos da elaboração e implementação de políticas públicas saudáveis, da criação de ambientes favoráveis à saúde e do desenvolvimento de habilidades pessoais (OMS, 1986). Nessa lógica, pondera-se que o PNAE vem se constituindo efetivamente como uma política saudável, principalmente a partir de sua articulação com a agricultura familiar, enquanto a escola reafirma-se como espaço privilegiado de construção de habilidades para a saúde, com significativo potencial para avançar enquanto ambiente saudável.

Quanto à periodicidade de entrega, constatou-se predominância da solicitação semanal ou entre uma e duas vezes ao mês, o que é coerente com a observação de que a maioria dos alimentos presentes nas chamadas são in natura ou minimamente processados (Tabela 2), visto que esses alimentos requerem entregas mais frequentes devido à sua perecibilidade. No entanto, é importante registrar que muitas prefeituras não definem a periodicidade das entregas nos editais, fazendo com que o agricultor não seja suficientemente esclarecido para decidir se tem realmente possibilidade de distribuição após sua habilitação. Para maior adequação dos agricultores, as chamadas precisam ser mais bem elaboradas, contendo não apenas a periodicidade da entrega, mas um cronograma descritivo com datas e quantidades estipuladas para entrega (BACCARIN et al., 2017). Sobre esse aspecto, estudo realizado com 201 chamadas públicas do ano de 2013, de municípios das diferentes regiões do país, observou não conformidades, destacando-se a ausência de cronograma em 93\% dos documentos (AGUIAR; CALIL, 2018).

A periodicidade de entrega está relacionada ao grau de processamento dos produtos demandados nas chamadas públicas. Segundo Guilhoto et al. (2006), os produtos de caráter familiar têm menor articulação com o setor industrial do que os da agricultura patronal. Assim, em cumprimento à Lei no 11.947/2009, os municípios 
devem priorizar a variedade de produtos direcionados à alimentação escolar, principalmente in natura, o que resulta em preferência por entregas semanais ou quinzenais (BRASIL, 2009a).

A falta dessas informações traz dificuldades para o agricultor, podendo influenciar negativamente sua decisão de participar do Programa ou, ainda, prejudicar seu atendimento aos compromissos assumidos, uma vez que ele não terá elementos suficientes ao adequado planejamento da logística para distribuição dos alimentos às escolas (BACCARIN et al., 2017). Nessa direção, cabe mencionar que a entrega muito descentralizada somente foi identificada no Vale do Itajaí, Norte e Oeste Catarinense, provavelmente pelo fato de que os maiores municípios do estado estão aí situados, o que implica número maior de escolas (UR). A entrega centralizada facilita para o agricultor participar do processo, reduzindo custos e dispêndio de tempo. Entretanto, a expressiva maioria das chamadas define mais de uma UR ou não apresenta informação a esse respeito, reafirmando-se que a logística de distribuição tem sido evidenciada como central para experiências bemsucedidas no fortalecimento da inserção da agricultura familiar no PNAE (MOSSMANN; TEO, 2017).

Argumenta-se que a entrega centralizada ou pouco descentralizada prevalentes, somadas, neste estudo - se deva mais ao porte dos municípios e ao menor número de escolas nas quais os produtos devem chegar do que, propriamente, à existência de centrais de recebimento nos municípios. A falta de centrais de recebimento, associada à reconhecida precariedade da infraestrutura física das escolas da rede pública, gera a necessidade de descentralizar e tornar mais frequentes as entregas, principalmente dos produtos de maior perecibilidade, como são predominantemente os da agricultura familiar.

Torna-se, assim, ainda mais relevante para o agricultor ter a informação sobre o número de UR, o que lhe confere capacidade de planejamento, organização e avaliação quanto aos preços que serão praticados, considerando os custos com o frete para a entrega dos alimentos, pois a legislação prevê que, no cálculo do preço a ser pago, estejam incluídas essas despesas (BRASIL, 2015b). Pondera-se que a ausência da informação sobre os preços, conforme constatado em $11 \%$ das chamadas analisadas, além de contrariar as disposições legais, exacerba as já apontadas dificuldades para o planejamento dos agricultores. É importante considerar que a legislação, ao estabelecer que sejam predefinidos e divulgados na chamada pública os preços a serem pagos, pretende evitar que os agricultores familiares concorram entre si por meio da redução dos preços de seus produtos. Além disso, essa observação reforça a importância de que os agentes envolvidos com a elaboração das chamadas públicas, nos municípios, sejam capacitados, de forma a qualificar o processo. 
Neste estudo, também se constatou reduzida presença de alimentos orgânicos nos editais analisados, o que pode decorrer da pouca oferta destes produtos, restringindo a compra aos poucos gêneros disponíveis e aos preços cobrados por seus produtores. Nesse sentido, estudo realizado em Santa Catarina indicou algumas causas para a pouca presença de alimentos orgânicos na alimentação escolar, como dificuldades para certificação e problemas de produção, o que resulta em baixa oferta (SILVA; SOUSA, 2013). No Rio Grande do Sul, entre as principais dificuldades, também foram apontadas a falta de certificação, a produção local insuficiente e o custo elevado (SANTOS et al., 2014). Essas considerações condizem com as de um estudo realizado em 2013, por meio do qual se constatou a solicitação de apenas um alimento orgânico em uma das 122 chamadas públicas divulgadas por 99 municípios de São Paulo (AMORIM; ROSSO; BANDONI, 2016).

Quanto aos preços, alimentos orgânicos certificados poderão ter acréscimo de até 30\% em relação aos correspondentes convencionais (BRASIL, 2015b). No entanto, a baixa escala de produção e o custo adicional de certificação, fiscalização e assistência técnica podem representar obstáculos à inserção mais expressiva de alimentos orgânicos da agricultura familiar no PNAE. A reduzida presença de alimentos integrais nos editais analisados indica a potencialidade de sua inserção no ambiente escolar. Para fortalecer essa inserção, é necessário realizar atividades de educação alimentar e nutricional que promovam maior aceitação, já que seu consumo não faz parte da realidade dos escolares. Segundo Verde e Olinda (2010), é preciso desenvolver atividades educativas que favoreçam mudanças nas práticas alimentares mais do que apenas acesso a conhecimentos.

No campo da prevenção e da terapêutica dietética, pontua-se a também reduzida presença de gêneros para necessidades alimentares especiais nos editais. Contudo, ao se considerar que em 2012 não se realizou compra destes alimentos, pondera-se que ocorreu um avanço nesse sentido no período de estudo. Tendo em vista que a prevalência de alergias e intolerâncias alimentares é crescente, evidencia-se a importância de adequar a aquisição de alimentos para a alimentação escolar a estas particularidades. Além disso, a Lei no 11.947/2009 prevê que os cardápios escolares atendam aos que necessitam de cuidado dietético especifico (BRASIL, 2009a). Estima-se que a aquisição de alimentos para atender necessidades dietéticas especiais possa ser comprometida pelo desconhecimento por parte dos nutricionistas gestores técnicos do PNAE sobre a existência de escolares nestas condições em seu âmbito de trabalho. Apresenta-se essa hipótese em decorrência das constatações de estudos anteriores sobre o tema, os quais relataram não ser usual que os nutricionistas do PNAE realizem atendimento a escolares com necessidades alimentares especiais 
(MELLO et al.,2012; SCARPARO et al.,2013).Para superar este obstáculo, é pertinente a criação de um fluxo intersetorial de informações que assegure a notificação e/ou a identificação dos casos que necessitam de alimentação especial. A esse respeito, Ribeiro et al. (2014) salientam que é importante reconhecer demandas e fortalecer a atenção a escolares com necessidades alimentares especiais, em uma perspectiva de educação inclusiva.

Uma política com potencial para prover suporte nesse sentido é o Programa Saúde na Escola, que tem, como diretrizes, a integração e articulação das redes públicas de ensino e saúde para o cuidado contínuo, ampliando o alcance e o impacto de suas ações relativas aos estudantes e suas famílias (RIBEIRO et al., 2014). Fica, portanto, reforçada a natureza intersetorial dessas políticas, e sua potência para o enfrentamento da complexidade das questões alimentares e nutricionais na atualidade. Nessa perspectiva, o PNAE, articulado à agricultura familiar, vem induzindo mudanças favoráveis no campo da segurança alimentar e nutricional, incidindo nos setores da saúde, educação, ambiente, agricultura, economia e desenvolvimento.

Cabe salientar que este estudo apresenta limitações, visto que sua principal fonte de dados é formada pelo conjunto de chamadas públicas dos municípios de Santa Catarina e que é possível que nem todos os produtos demandados tenham sido efetivamente adquiridos. Ainda é preciso considerar que cerca de metade dos municípios do estado não divulgou amplamente editais no período avaliado. Contudo, argumenta-se que os documentos localizados e os resultados obtidos permitiram realizar uma caracterização da aquisição de alimentos da agricultura familiar para a alimentação escolar no estado, apontando seus pontos fortes e algumas fragilidades. Pondera-se que esses editais representam fontes adequadas de dados para os fins pretendidos, com baixo custo de coleta e processamento, requerendo equipe mínima. Além disso, os indicadores propostos neste estudo proporcionam uma visão de processo, capaz de evidenciar avanços e fragilidades tanto no âmbito da alimentação e nutrição quanto no que diz respeito a aspectos que possam favorecer ou dificultar a participação dos agricultores no PNAE.

\section{Considerações finais}

Em conclusão, os resultados deste estudo indicaram que a divulgação dos editais para compra da agricultura familiar ainda não é ampla como previsto na legislação, embora esse indicador tenha evoluído favoravelmente no período, haja vista o aumento do número de municípios que publicaram chamadas em seus sites na internet. Esta pesquisa observou, também, que a maioria dos municípios do estado atendeu ao art. 14 da Lei no 11.947/2009 (BRASIL,2009a), e que essa proporção aumentou ao longo do período.Com relação à origem e ao grau de processamento, constatou-se predomínio dos alimentos in natura e minimamente processados e dos de origem vegetal. Já 
a demanda por alimentos orgânicos, integrais e para necessidades especiais foi incipiente. Quanto aos aspectos logísticos, predominaram entregas centralizadas e pouco descentralizadas, com periodicidade semanal ou entre uma e duas vezes ao mês. Destaca-se a ausência em proporção relevante dos editais de informações sobre periodicidade e número de locais de entrega, além de que $11 \%$ deles não apresentavam a tabela de preços prefixados.

Embora esses achados sejam iniciais, já permitem perceber a oferta de alimentos mais saudáveis no ambiente escolar. Apesar de esse movimento ser mais expressivo em algumas mesorregiões, o acompanhamento desses indicadores de forma prospectiva e a disseminação dos resultados correspondentes poderá contribuir para a efetiva implementação da Lei do PNAE (BRASIL, 2009a), produzindo correções e melhorias nesse processo, com reflexos no desenvolvimento local e na qualidade da alimentação que os estudantes acessam na escola.

\section{Referências}

AGUIAR, J. A.; CALIL, R. M. Análise da adequação normativa de chamadas públicas para compra de alimentos dos agricultores familiares destinados ao Programa Nacional de Alimentação Escolar. Higiene Alimentar, São Paulo, v. 31, n. 278/279, p. 22-29, out. 2018.

AMORIM, A. L. B.; ROSSO, V. V.; BANDONI, D. H. Acquisition of family farm foods for school meals: analysis of public procurements within rural family farming published by the cities of São Paulo state. Revista de Nutrição, Campinas, v. 29, n. 2, p. 297-306, mar./abr. 2016.

BACCARIN, J. G. et al. Indicadores de avaliação das compras da agricultura familiar para alimentação escolar no Paraná, Santa Catarina e São Paulo. Revista de Economia e Sociologia Rural, Brasília, v. 55, n. 1, p. 103-22, jan./mar. 2017.

BAPTISTA, T. W. F; MATTOS, R. A. Sobre Política (ou o que achamos pertinente refletir para analisar políticas). In: BAPTISTA, T. W. F; MATTOS, R. A. (Org.) Caminhos para Análise das Políticas de Saúde. Porto Alegre: Rede Unida, 2015. p. 83-149.

BRASIL. Fundo Nacional de Desenvolvimento da Educação (FNDE). Lei $n^{\circ}$ 11.947, de 16 de junho de 2009a. Dispõe sobre o atendimento da Alimentação escolar e do Programa Dinheiro Direto na Escola. Diário Oficial [da] República Federativa do Brasil, Brasília, DF, 17 jun. 2009. Seção 1, p. 2.

BRASIL. Resolução/CD/FNDE no 38, de 16 de julho de 2009b. Dispõe sobre o atendimento da alimentação escolar aos alunos da educação básica no Programa Nacional de Alimentação Escolar (PNAE). Diário Oficial [da] República Federativa do Brasil, Brasília, DF, 17 jun. 2009. Seção 1, p. 10.

BRASIL. Ministério da Educação. Fundo Nacional de Desenvolvimento da Educação. Resolução no 26, de 17 de junho de 2013. Dispõe sobre o atendimento da alimentação escolar aos alunos da educação básica no âmbito do Programa Nacional de Alimentação Escolar - PNAE. Diário Oficial [da] República Federativa do Brasil, Brasília, DF, 18 jun. 2013. Seção 1, p. 7. 
BRASIL. Ministério da Educação. Fundo Nacional de Desenvolvimento da Educação. Manual de aquisição de produtos da agricultura familiar para a alimentação escolar. 2. ed. Brasília: Ministério da Educação, 2016. Disponível em: http://www.fnde.gov.br/programas/pnae/pnae-area-para-gestores/pnae-manuaiscartilhas. Acesso em: 10 fev. 2018.

BRASIL. Ministério da Saúde. Secretaria de Atenção à Saúde. Departamento de Atenção Básica. Guia alimentar para a população brasileira. 2. ed. Brasília: Ministério da Saúde, 2014a.

BRASIL. Ministério da Saúde. Ministério do Desenvolvimento Agrário. O encontro da agricultura Familiar com a alimentação escolar. Brasília: Ministério da Educação, 2014b. Disponível em: https://www.fnde.gov.br/ programas/pnae/pnae-area-para-gestores/pnae-manuais-cartilhas?start=10. Acesso em: 30 set. 2017.

BRASIL. Fundo Nacional de Desenvolvimento da Educação. Dados Agricultura Familiar 2012-2014. Brasília: FNDE, 2015a. Disponível em: http://www.fnde. gov.br/programas/alimentacao-escolar/ alimentacao-escolar-consultas/dados-daagricultura-familiar. Acesso em: 20 jul. 2018.

BRASIL. Resolução/CD/FNDE no 4, de 2 de abril de 2015b. Altera a redação dos artigos 25 a 32 da Resolução/CD/FNDE no 26, de 17 de junho de 2013, no âmbito do Programa Nacional de Alimentação Escolar (PNAE). Diário Oficial [da] República Federativa do Brasil, Brasília, DF, 3 abr. 2015. Seção 1, p. 10.

BRASIL. Ministério da Educação. Fundo Nacional de Desenvolvimento da Educação. Manual de aquisição de produtos da agricultura familiar para a alimentação escolar. 2. ed. Brasília: Ministério da Educação, 2016. Disponível em: http://www.fnde.gov.br/programas/pnae/pnae-area-para-gestores/pnae-manuaiscartilhas. Acesso em: 10 fev. 2018.

BRASIL. Ministério da Educação. Fundo Nacional de Desenvolvimento da Educação. Contas Online: Manual do Usuário: SiGPC - Sistema de Prestação de Contas. 2. ed. Brasília: FNDE, 2017. Disponível em: http://www.fnde.gov.br/ fnde_sistemas/sigpc-contas-online. Acesso em: 5 jul. 2018.

BUNDY, D. et al. Rethinking school feeding: social safety nets, child development, and the education sector. Washington: World Bank, 2009.

CARVALHOSA, C. S.; BURLANDY, L. Análise da trajetória de inclusão da agricultura familiar no programa nacional de alimentação escolar no Brasil. Revista UNIABEU, Belford Roxo, v. 10, n. 26, p. 244-259, ago./dez. 2017.

CERVATO-MANCUSO, A. M. et al. O papel da alimentação escolar na formação dos hábitos alimentares. Revista Paulista de Pediatria, São Paulo, v. 31, n. 3, p. 324-30, set. 2013.

DOMENE, S. M. A. A escola como ambiente de promoção da saúde e educação nutricional. Psicologia USP, São Paulo, v. 19, n. 4, p. 505-517, out./dez. 2008.

ESPEJO, F.; BURBANO, C.; GALLIANO, E. Home Grown School Feeding: a framework to link school feeding with local agricultural production. Rome: United Nations World Food Programme (WFP), 2009. Disponível em: http:// hgsf-global.org/en/what-is-hgsf. Acesso em: 12 ago. 2018.

FOOD AND AGRICULTURAL ORGANIZATION (FAO). Alimentar o mundo, cuidar do planeta. Montevideo: FAO, 2014. Disponível em: http://www.fao.org/ fileadmin/user_upload/iyff/pdf/ES_IYFF_BROCHURE.pdf.Acesso em: 12 ago. 2018. 
GIL, A. C. Como classificar as pesquisas? In: GIL, A. C. Como elaborar projetos de pesquisa. 4 ed. São Paulo: Atlas, 2008. p. 41-58.

GONÇALVES, H. V. B. et al. Family farming products on menus in school feeding: a partnership for promoting healthy eating. Ciência Rural, Santa Maria, v. 45, n. 12, p. 2267-2273, dez. 2015.

GUILHOTO, J. et al. A importância do agronegócio familiar no Brasil. Revista de Economia e Sociologia Rural, Brasília, v. 44, n.3, p. 355-82, jul./set. 2006.

HAMMER, O.; HARPER D. A. T.; RIAN, P. D. Past: Palaeonthological statistics software package for education and data analysis. Version 1.37,2001. Disponível em: http://palaeo-electronica.org/2001_1/past/issue1_01.htm. Acesso em: 21 mar. 2016.

HONGYU, K.; SANDANIELO, V. L. M.; OLIVEIRA JUNIOR, G. J. Análise de Componentes Principais: resumo teórico, aplicação e interpretação. E\&S Engineering and Science, Cuiabá, v. 1, n. 5, p. 83-90, jul. 2015.

INSTITUTO BRASILEIRO DE GEOGRAFIA E ESTATÍSTICA (IBGE). Censo Agropecuário: Agricultura Familiar 2006. 2006. Disponível em: https:// www.ibge.gov.br/estatisticas/economicas/agricultura-e-pecuaria/21814-2017censo-agropecuario.html?=\&t=downloads Acesso em: 15 maio 2019.

INSTITUTO BRASILEIRO DE GEOGRAFIA E ESTATÍSTICA (IBGE). Cidades. Rio de Janeiro: IBGE, 2010a. Disponível em: http://www.ibge.gov.br/ estatisticas-novoportal/por-cidade-estado-estatisticas.html? $t=$ destaques\&c=42. Acesso em: 18 jul. 2018.

INSTITUTO BRASILEIRO DE GEOGRAFIA E ESTATÍSTICA (IBGE). Pesquisa de orçamentos familiares 2008-2009: avaliação nutricional da disponibilidade domiciliar de alimentos no Brasil. Rio de Janeiro: IBGE, 2010b. Disponível em: https://biblioteca.ibge.gov.br/visualizacao/livros/liv47310.pdf. Acesso em: 20 jul. 2018.

LOUZADA, M. L. C. et al. Impacto de alimentos ultraprocessados sobre o teor de micronutrientes da dieta no Brasil. Revista de Saúde Pública, São Paulo, v. 49, n. 45, p. 1-8, ago. 2015.

MARCONDES, T. Mudanças no espaço rural de Santa Catarina. In: VIEIRA, L. M. Síntese Anual da Agricultura de Santa Catarina 2009-2010. Florianópolis: EPAGRI, 2010. p. 12-24.

MATTEI, L. Novo retrato da agricultura familiar em Santa Catarina. In: Vieira, Luiz Marcelino. Síntese Anual da Agricultura de Santa Catarina 2009-2010. Florianópolis, EPAGRI, 2010. p. 25-35.

MELLO, A. L. et al. Perfil do nutricionista do programa nacional de alimentação escolar na região Nordeste do Brasil. Revista de Nutrição, Campinas, v. 25, n. 1, p. 119-132, jan./fev. 2012.

MIOR, L. C. et al. Redes, agroindústrias familiares e os novos mercados em Santa Catarina. In: ESTEVAM, D. O.; MIOR, L. C. Inovações na agricultura familiar: as cooperativas descentralizadas em Santa Catarina. Florianópolis: Insular, 2014.p. 21-53.

MONTEIRO, C. A. et al. Nova. The star shines bright. World Nutrition, London, v. 7, n. 1-3, p. 28-38, jan./mar. 2016.

MOSSMANN, M. P.; TEO, C. R. P. A. Alimentos da agricultura familiar na alimentação escolar: percepções dos atores sociais sobre a legislação e sua implementação. Interações, Campo Grande, v. 18, n. 2, p. 31-43, abr./jun. 2017. 
ORGANIZAÇÃO MUNDIAL DA SAÚDE (OMS). Carta de Ottawa. I Conferência Internacional sobre Promoção da Saúde. Canadá: OMS, 1986.

RIBEIRO, C. S. G. et al. Necessidades alimentares especiais em ambiente escolar: um ensaio sobre a interface entre ciências da Nutrição e Bioética. Demetra, Rio de Janeiro, v. 9, n. 3, p. 633-643, 2014.

SANTOS, F. dos et al. Avaliação da inserção de alimentos orgânicos provenientes da agricultura familiar na alimentação escolar, em municípios dos territórios rurais do Rio Grande do Sul, Brasil. Ciência e Saúde Coletiva, Rio de Janeiro, v. 19, n. 5, p. 1429-1436, maio 2014.

SARAIVA, E. B. et al. Panorama da compra de alimentos da agricultura familiar para o Programa Nacional de Alimentação Escolar. Ciência e Saúde Coletiva, Rio de Janeiro, v. 18, n. 4, p. 927-935, abr. 2013.

SCARPARO, A. L. S. et al. Formação para nutricionistas que atuam no Programa Nacional de Alimentação Escolar: uma avaliação da efetividade. Ciência e Saúde Coletiva, Rio de Janeiro, v. 18, n. 4, p. 1001-1008, abr. 2013.

SILVA, A. P. F.; SOUSA, A. A. Alimentos orgânicos da agricultura familiar no Programa Nacional de alimentação Escolar do Estado de Santa Catarina, Brasil. Revista de Nutrição, Campinas, v. 26, n. 6, p. 701-14, nov./dez. 2013.

SOARES, F.V. et al. Structured Demand and Smallholder Farmers in Brazil: the case of PAA and PNAE. Brasília: IPC/WFP, 2013. Disponível em: http://www. ipc-undp.org/pub/IPCTechnicalPaper7.pdf. Acesso em: 20 jul. 2018.

TEO, C. R. P. A.; MONTEIRO, C. A. Marco legal do Programa Nacional de Alimentação Escolar: uma releitura para alinhar propósitos e prática na aquisição de alimentos. Revista de Nutrição, Campinas, v. 25, n. 5, p. 657-668, set./out. 2012.

TEO, C. R. P. A.; MOSSMAnN, M. P.; TAGLIETTI, R. L. Desafios e mecanismos de enfrentamento na relação entre agricultura familiar e alimentação escolar. Grifos, Chapecó, v. 26, n. 43, p. 35-64, jul./dez. 2017.

TRICHES, R. M.; SCHNEIDER, S. Alimentação escolar e agricultura familiar: reconectando o consumo à produção. Saúde e Sociedade, São Paulo, v. 19, n. 4, p. 933-945, out./dez. 2010.

TRICHES, R. M.; SCHNEIDER, S. Desestruturar para construir: interfaces para agricultura familiar acessar o Programa de Alimentação Escolar. Revista Estudos Sociedade e Agricultura, Rio de Janeiro, v. 20, n. 1, p. 66-106, abr. 2012.

VERDE, S. M. M. L.; OLINDA, Q. B. Educação Nutricional: uma ferramenta para alimentação saudável. Revista Brasileira de Pesquisa em Saúde, Fortaleza, v. 23, n. 3, p. 197-98, jul./set. 2010.

ZOLDAN, P. O PIB e a evolução recente da economia catarinense. In: VIEIRA, L. M. Síntese Anual da Agricultura de Santa Catarina 2009-2010. Florianópolis: EPAGRI, 2010. p. 7-11.

Recebido: 26/12/2018.

Aceito: 16/05/2019. 


\title{
ACQUISITION OF FOODS FROM FAMILY FARMING FOR SCHOOL FEEDING IN SANTA CATARINA, 2012-2014
}

\begin{abstract}
This study deals with public policies related to family agriculture and its relationship with school feeding. The objective was to evaluate the characteristics of the food acquisition from family farming for school feeding in Santa Catarina state from 2012 up to 2014. It is a documentary study, having as data sources documents of public access on resource application and acquisition of food from family farming. The variables were application of financial resources, origin and food processing degree, demand for organic, whole and special needs food, periodicity and delivery points, and purchase price information. Frequency analysis and Principal Component Analysis (PCA) were performed. The proportion of municipalities that applied $30 \%$ or more of the federal resources received in family agriculture ranged from 60,2 to $72,2 \%$. The 300 purchase notices (public calls) issued by 147 municipalities showed that: $64.2 \%$ of the food demanded were vegetables; $44,8 \%$ in natura; $14,4 \%$ ultraprocessed. The demand for organic, whole and special needs foods was incipient, being present in $21(7 \%), 61(20,3 \%)$ and $13(4,3 \%)$ public calls, respectively. Centralized/ non-decentralized delivery predominated in the public calls $(71 ; 23,7 \%)$, with weekly delivery or between one to two times/month for $87,5 \%$ (1.284) of food. Information on the purchase prices was absent in 33 (11\%) notices. The PCA explained $98,1 \%$ of the food demanded variation in Santa Catarina mesoregions, according to the year and processing degree. We concluded school food supply has become healthier, but public calls need to be better elaborated to favor this process.
\end{abstract}

Keywords: School Feeding. Diet, Food, and Nutrition. Intersectoral Collaboration. Nutrition Programs and Policies. School Health Services.

\section{ADQUISICIÓN DE ALIMENTOS DE AGRICULTURA FAMILIAR PARA LA ALIMENTACIÓN ESCOLAR EN SANTA CATARINA, 2012-2014}

\begin{abstract}
Resumen
Este estudio aborda políticas públicas relativas a la agricultura familiar y su relación con la alimentación escolar. E1 objetivo fue evaluar características de la adquisición de alimentos de la agricultura familiar para la alimentación escolar en Santa Catarina, en 2012-2014. Se trata de estudio documental, teniendo como fuentes documentos de acceso público sobre aplicación de recursos y adquisición de alimentos de la agricultura familiar. Las variables fueron: aplicación de recursos, origen/grado de procesamiento, demanda de alimentos orgánicos, integrales y para necesidades especiales, periodicidad y puntos de entrega, información sobre precios. Se realizaron análisis de componentes principales (PCA) y de frecuencias. La proporción de municipios que aplicó el 30\% o más de los recursos recibidos en la agricultura familiar varía de 60,2 a 72,2\%. Los 300 edictos (llamados públicos) divulgados por 147 municipios evidenciaron que: $64,2 \%$ de los alimentos demandados eran vegetales; $44,8 \%$ in natura; $14,4 \%$ ultraprocesados. La demanda de alimentos orgánicos, integrales y para necesidades especiales fue incipiente, presentes en 21 (7\%), 61 (20,3\%) y 13 (4,3\%) edictos, respectivamente. La entrega centralizada/poco descentralizada predominó en los edictos (71,23,7\%), con entrega semanal o entre una a dos veces/mes para 87,5\% (1.284) de los alimentos. La información sobre los precios estuvo ausente en 33 (11\%) edictos. La PCA explicó 98,1\% de la variación de alimentos en las mesorregiones, segundo año y grado de procesamiento. Se concluye que la oferta de alimentos en la escuela se ha vuelto más saludable, pero los edictos necesitan ser mejor elaborados para favorecer ese proceso.
\end{abstract}

Palabras clave: Alimentación Escolar. Nutrición, Alimentación y Dieta. Colaboración Intersectorial. Programas y Políticas de Nutrición y Alimentación. Servicios de Salud Escolar. 